\title{
Curriculum reform as a driver for change in higher education: the case of South Africa
}

\section{Bruce Kloot}

\begin{abstract}
A recent proposal by the Council for Higher Education (CHE) outlines a solution to the persistently low and racially skewed completion rates in South African higher education. This involves lengthening the curricula of all qualifications through the insertion of 120 credits of 'foundational provision'. This article provides a critique of this strategy by exploring its origins and placing South African efforts at improving student access and success in the international context. It draws on the narratives of two academics, one a top research professor and the other a foundation programme lecturer, employing the theoretical lens of Pierre Bourdieu to examine higher education as a social space or field. This analysis suggests that the power structure of higher education itself is likely to constrain the effectiveness of the CHE's proposal and ultimately fail to shift the low and racially skewed completion rates that plague South African higher education.
\end{abstract}

\section{Introduction}

Higher education has experienced remarkable growth in the last half-century. Across the globe, the proportion of school-leavers attending higher education institutions has increased fivefold since 1970 while the population has but doubled (Unterhalter and Carpentier, 2010). According to Schofer and Meyer (2005, p.918) increased democratisation, the scientization of society and the rise of national development logics have brought about what is today a "highly expanded, and essentially global, system of higher education". This has eroded the autonomy of higher education institutions. On the one hand a post-Fordist work order has resulted in a call for the development of "high skills" (Finegold and Soskice, 1988) in the economically active members of the population, placing demands on higher education to produce "knowledge workers" (Bell, 1975) for the global economy. On the other hand, in the wake of increased democratic participation and the expansion of human rights, the state is pressing higher education more than ever to deal with issues of equity. The call to improve access or to 'widen participation' for students from 
'non-traditional' groups has become an important thrust of education policy, especially in the UK, Europe and the United States.

Unfortunately, greater access has not translated into more equitable outcomes; while participation rates have improved, retention rates have been more difficult to shift. A recent study conducted for the Higher Education Funding Council for England (HEFCE) that examined the effectiveness of widening participation initiatives in six nations revealed that, in general, students from "target groups are less likely to complete their studies" than students from traditional groups (2013, p.33). This contributes to a body of literature exploring the effectiveness of efforts to improve the performance of non-traditional or 'minority' students (Tinto, 1975; Clewell and Ficklen, 1986; Banks and Banks, 1993; Rollnick, 2010). While there is no clear solution to the problem of high attrition among non-traditional students, there is consensus that "systemic/structural change within the universities themselves" (Morey, 2000) is required if the equity agenda is to be taken seriously.

The difficulties associated with bringing about systemic change are no better demonstrated than in the case of South Africa, one of the countries included in the HEFCE study referred to above. Compared to Australia, the United States and three European nations, South Africa is singled out as having "considerably lower" completion rates $(2013$, p.33). The South African report notes that drop-out rates "remain a huge concern with approximately $50 \%$ of students (undergraduates and postgraduates) not completing their qualifications" (Wangenge-Ouma, 2013, p.28). This is attributed to "the architecture of the apartheid education system" (HEFCE, 2013, p.18) and the difficulties in transforming higher education in the post-apartheid era. Although the legacy of apartheid education is unique, there are many ways in which South African higher education is comparable to education systems in other parts of the world. Firstly, the foundations of South African higher education were transplanted from Scotland in the 1800s and institutions developed along the lines of universities in the UK (Phillips, 2003). Secondly, there was opposition from within higher education to the policies of separate education and transformation efforts in a number of universities began a decade before apartheid was dismantled. Finally, education policy in South Africa after the fall of apartheid, after a period of robust negotiation, reflects the forces of globalisation impinging on higher education systems worldwide (Davies, 1996). A review of higher education policy after 10 years of democracy in South Africa noted that 


\begin{abstract}
discursive tensions between equity and development were sustained in the debates of stakeholders. The 'economic rationalist' position was endorsed in a policy focus on the development of higher skills to meet the needs of economic development and global competitiveness. . . The 'popular democratic' position was endorsed in the declared commitment to a programme of redress (CHE, 2004, p.232).
\end{abstract}

The endeavour to widen participation in the South African context, and to ensure that the students from non-traditional backgrounds who have gained access to higher education also have a reasonable chance of success, is therefore relevant to education systems worldwide.

This article deals with a recent proposal by the Council for Higher Education (CHE) in South Africa to reform the national curriculum. A critique of such a proposal is timely given the recent attention to the need for universities to adapt their curricula for the global marketplace (Blackmore and Kandiko, 2012) through curriculum various reform initiatives (Pegg, 2013). The CHE proposal is outlined below and the theoretical tools of Pierre Bourdieu are used to understand how academic practice will be affected, especially in relation to teaching. While many of the issues are addressed in the literature on curriculum reform in the context of a diversifying student body (Ognibene, 1989; Morey and Kitano, 1997; Warren, 2002), it is hoped that a more critical approach will shed light on the difficulties associated with curriculum reform in the context of a research-intensive university. The intention is to deepen the conversation about the likely effectiveness of such a large-scale curriculum reform exercise and to prompt reflection about strategies to improve success in higher education in other contexts.

\title{
The flexible curriculum proposal
}

The proposal (CHE, 2013) begins by providing updated data on the participation and completion rates prevalent in the system. It confirms the findings of previous studies (Scott, Yeld and Hendry, 2007) that participation rates are both low and racially skewed. In 2011, only 14\% of black ${ }^{1}$ African

The term 'black' in the proposal and in this article refers to those categorised as non-white under the apartheid government. This includes those classified as black African, 'coloured' and Indian. It is acknowledged here that 'race' was used as a construct to institutionalise oppression in South Africa and such references are not intended to entrench racial classification. However, given the subject of this article, it is impossible to avoid the use of these designators. 
youth, the non-traditional - and majority - population group in the South Africa case, attended higher education compared to 57\% for whites (CHE, 2013). In terms of completion rates, the proposal draws on the latest cohort analyses to show that only $48 \%$ of all students registering for undergraduate qualifications in 2006 at the contact institutions ${ }^{2}$ graduated within five years (CHE, 2013). Not surprisingly, these figures are skewed by race: only $42 \%$ of black African students as opposed to $61 \%$ of white students graduated within five years. "The net result of these disparities in access and success is that under 5\% of African and coloured youth are succeeding in any form of higher education" (CHE, 2013, p.15).

Based on these numbers, the proposal argues that the curriculum should not be structured for the minority who complete their studies in minimum time but instead for the majority who take longer than this to complete. The proposed solution is thus a large-scale curriculum reform strategy that entails adding a year to all tertiary qualifications: "it is not feasible to substantially improve graduate output and outcomes without extending the formal time of core first degrees and diplomas, in the interests of the majority of the student intake" (CHE, 2013, p.19). However, since an "appreciable minority" of students are able to graduate in regulation time (three years for most degrees and diplomas or four years for a degree such as engineering) the proposal makes provision for such students within an 'accelerated stream' which is to run alongside the extended version. Disciplinary exemplars are provided in the proposal to demonstrate how the regular and modified curricula structures can run in parallel. In essence, what is being proposed

\begin{abstract}
is a flexible curriculum structure that establishes new mainstream parameters of duration, starting point and progression pathways - allowing for coherently-designed curricula that meet the needs of the majority - and that also makes provision for shorter pathways within the new norms (CHE, 2013, p.19).
\end{abstract}

Rather than adding a year at the start of all qualifications - the foundation programme model - the strategy is to insert what is known as "foundational provision" at strategic points to ensure that developmental work is threaded through the curriculum. The "only way" of overcoming obstacles to progression, the proposal argues, is to "put forms of developmental provision

This for all three- and four-year undergraduate qualifications, excluding those offered by UNISA (University of South Africa), one of the largest distance education institutions in the world. 
in place at appropriate stages of the curriculum" (CHE, 2013, p.18). In a newspaper article, Shay (2014) explains how this will shift completion rates:

The flexible degree enables curriculum space (an extra 120 credits) for 'foundational provision' where foundational provision is spread, perhaps rather thickly in first year but threads its way through years two, three and four with particular provision for those 'killer courses', courses which are notoriously difficult and present real bottlenecks for students. If this 'foundational provision' 'works' - and there are 30 years of educational development experience to draw on - fewer students fail, completion rates improve. It's simple.

In order to properly engage with the strategy outlined in the flexible curriculum proposal, it is necessary to understand its origins. This requires a brief foray into the ' 30 years of educational development experience' referred to above. Elsewhere in the Anglophone world, education development mostly refers to staff development (Amundsen and Wilson, 2009) but in South Africa, concerns about equity and student development are a distinct emphasis (Brew, 2002; Clegg, 2009). The fact that this movement - actually more often called 'academic development' in South Africa - started 30 years ago, means that it began in the mid-1980s, a full decade before the dismantling of apartheid.

It is significant that, early on, foundation programmes emerged as the principle strategy of this movement. In the UK, foundation degrees generally refer to qualifications designed with the help of employers to combine academic study with workplace learning degrees (Harvey, 2009). However, in the South African context, foundation programmes are curriculum interventions aimed at assisting educationally disadvantaged students to make the transition to higher education. As such, they are entry-level, credit-bearing programmes catering for full-time students, most of whom are experiencing tertiary study for the first time. As mentioned above, foundation programmes initially referred to the insertion of an additional year at the start of a qualification. This shifted over the years as academic development evolved and, as will be explained in the next section, foundation programmes became more integrated with the 'mainstream', the term used in South Africa to designate the traditional offering. Although it is not possible to go into all the details, it is argued here that the foundation programme strategy contained the seeds of the flexible curriculum proposal. 
Foundation programmes as a strategy of academic development

Foundation programmes were developed not only for students to 'bridge the gap' from an inadequate secondary school background, but to "build a foundation for meaningful learning" (Grayson, 1996, p.993) for their tertiary studies. Early on, it was argued by academic development (AD) practitioners that the mainstream needed to adjust to cater for the needs of a diversifying student group. It is maybe less well known that foundation programmes were also intended to pave the way for large-scale curriculum reform:

\footnotetext{
... if bridging programmes are successful in drawing in ever-increasing numbers of students, the time may come when they become the 'norm' and may be incorporated into the regular academic structures of the university. There are in any case already some strong arguments in favour of adding a year to our current degree programmes; bridging programmes may prove, in future years, to have paved the way for this development (Scott, 1986, pp.24-25).
}

Although he calls them 'bridging programmes', Scott (1986) distinguishes these programmes from adjunct (separate, pre-first-year) bridging programmes that were a popular approach at the time. In order to understand the significance of this distinction, it is necessary to provide some context.

Although black students were officially prohibited from attending so-called 'white' universities during the early decades of the apartheid era, small numbers of black students began trickling on to the campuses of English-medium universities in the early 1980s. This set of institutions, which had some history of opposition to apartheid education, established small inter-faculty units called Academic Support Programmes (ASPs) to support these students. Adjunct bridging programmes became a popular approach for dealing with the situation in the early 1980s; another strategy involved the provision of extra tutorials, the 'concurrent' support model. However, both of these approaches were deemed unsatisfactory by many practitioners and it was in this context that Ian Scott, Director of the ASP at the University of Cape Town (UCT) at the time, wrote his paper entitled Tinkering or Transforming? (Scott, 1986) from which the quotation above is taken. Although he was not the first to do so (see Stanton, 1987), Scott asserted that a particular form of bridging programme, one that properly articulated with regular courses within specific discipline areas, was required if the academic support movement was going to have a meaningful impact. 
The advantage of this strategy, according to Scott, was that these programmes would not be bound by the parameters of regular courses like the concurrent tutorial support model and their integrated nature would mean that they were more appropriately forward-looking than separate bridging programmes. They could thus provide the opportunity to concentrate "on addressing the students' fundamental learning needs, and. . thus provide a solid foundation for real competence and independence" (Scott, 1986, p.23, ${ }^{3}$ emphasis added). These programmes came to be called 'foundation programmes'. Scott also mentions the issue of accreditation, describing it as a "major problem", suggesting that "every effort should be made to persuade the university to grant at least partial credit" (1986, p.23) for these programmes.

The events in the 1990s leading up to the democratic transition prompted tertiary institutions to take ownership of the phenomena of 'disadvantage' and 'underpreparedness', signalling the shift from the paradigm of academic support to academic development (Volbrecht and Boughey, 2004). While university management at English-medium white universities had always been sympathetic towards academic support, AD meant an official acknowledgment of the issues and recognition of the importance of organisational structures (i.e. academic development units). This was accompanied by developments at the theoretical level among academic development practitioners who argued for a more 'infused' approach to student support (Boughey, 2012) and thus changes to the mainstream. At this stage there was a more widespread implementation of programmes to try to deal with the issues.

While most programmes at the (now so-called) 'historically' white English-medium universities followed this trajectory, practitioners at many of the historically black and white Afrikaans-medium institutions attempted to 'reinvent the wonky wheel', in the words of Chrissie Boughey (2007), implementing adjunct bridging programmes or concurrent tutorial support courses. Some universities sought the help of more experienced practitioners at English-medium universities and in this way there was some sharing of ideas but, according to Kotecha, Allie and Volmink, practice was "institutionally based and fragmented" and there was "little consolidation of ideas" (1997, p.4).

This is actually page 24 of the paper. Pages 23 and 24 are mistakenly swopped around. 
This fragmentation was perhaps inevitable given their origins, the historical divisions within the sector along the lines of 'race' and language, and the minority status afforded educational development in general. It also has to do with the autonomy of higher education relative to the political realm and the inordinate amount of time that it took for the new Department of Education (DoE) to implement a co-ordinated strategy of redress. Foundation programmes - or what were called 'extended curricula' - were included in the 1997 White Paper and were to be given "due weight and status as integral elements of a higher education system committed to redress and to improving the quality of learning and teaching" (Department of Education, 1997, Section 2.34). However, it took six more years before extended curricula were included in the higher education funding framework (Saunders, 2011). Ian Scott (2001) argued for public funding for extended curricula, one of the criteria being that they contain "additional foundational elements [that] articulate successfully with the standard curriculum" (p.6).

After a few rounds of 'foundation grants' to pilot the model, the Ministry of Education released Funding for Foundational Provision in Formally Approved Programmes (DoE, 2006). According to this framework, which drew heavily on the recommendations of Scott (2001), only formally accredited programmes extended or augmented by some form of foundational provision component would benefit from the substantial funds allocated, some R367m for the 2007/8-2009/10 triennium. Moreover, the foundational component had to be "formally planned, scheduled and regulated as an integral part of the programme" (DoE, 2006, p.3). After two cycles of earmarked funding allocated on the basis of institutional applications, funding for extended programmes was transferred to three-year rolling cycles in 2013 which means that they are now funded in the same way as other higher education courses.

It is in this socio-historical and policy context that we must consider the flexible curriculum proposal. The evolution of foundation programmes from bridging programmes to a foundational provision component which is linked with regular programme offerings through funding and policy seems to suggest that the next step is a large-scale curriculum reform strategy. Indeed, the proposal itself (CHE, 2013) contains a review of the developments described above and a discussion of the successes and limitations of extended programmes in order to make a case for mainstream curriculum reform. These limitations are explicitly linked to the low status of foundation programmes. Consider the following excerpt: 


\begin{abstract}
However, the problems inherent in the current extended programme model, arising primarily from its minority and marginalised status, impose intractable limitations on its success. It is interesting that early writing about foundational provision, going back to the 1980 s, indicates that the model was not seen as a permanent solution but rather as paving the way for mainstream curriculum reform (CHE, 2013, p.90).
\end{abstract}

The urgent need for decisive intervention in South African higher education, the apparent inevitability of the step towards mainstream curriculum reform and a concrete solution in the form of the flexible curriculum proposal are a persuasive combination. Indeed, the proposal can be considered the destination of the educational development movement in South Africa, the culmination of three decades of struggle for the transformation of higher education. If the proposal is implemented, the words of Scott (1986) will have proven to be remarkably prescient.

The remainder of this article focuses on whether modifying the curriculum to accommodate the majority of students will be an effective driver for change. This is to be accomplished using Bourdieu's theoretical tools to analyse academic development practice in the context of the field of higher education. The proposal suggests that lengthening the curriculum for all core undergraduate programmes is a "necessary condition for improving student learning" (CHE, 2013, p.107) but from a field perspective, what is important is how the curriculum is enacted. How seriously will mainstream staff, who will largely be responsible for teaching the redesigned curricula, take its aims and intentions? Will they have the required understanding and the will to change their practice (Boughey, 2013) in line with the intentions and aims of the proposal?

\title{
Theoretical framework
}

Bourdieu is well known for the notion of 'cultural capital' which he uses to explain the tendency of students from privileged backgrounds to outperform working class students in assessment tasks because of their familiarity with middle class culture (Bourdieu and Passeron, 1977). However, rather than focusing on how the cultural capital of students influences performance in education generally, this article focuses on the social space of higher education and how this shapes the practices of academics in relation to undergraduate teaching. Central to this analysis is the notion of fields, a concept that Bourdieu uses to describe the ensemble of relatively autonomous social spaces within society. Maton (2005, p.689-690) explains that fields are 
autonomous in that they generate their own values and markers of achievement but this autonomy is relative in that these values "are not alone in shaping a field; economic and political power also play a role". The focus of this analysis is thus on the field of higher education as a social space, distinct from the political realm and the field of secondary education.

In Homo Academicus, Bourdieu (1988) identifies the two forms of power operating in the university field - academic capital which corresponds with the heteronomous principle and intellectual (or scientific) capital which corresponds with the inward-looking, autonomous principle of 'knowledge for its own sake'. These forms of power are simply economic and cultural capital respectively which have been reinterpreted in the university field. Academic capital is more temporal and is linked to the instruments of reproduction and corresponds with position in the institutional hierarchy (Bourdieu 1988) while intellectual capital is linked to 'scientific renown' and is governed by the 'logic of research'.

According to Bourdieu, social action within a field can be characterised as a game that agents 'play' as they attempt to dominate the field through accumulating the forms of capital available. Agents struggle to accumulate these forms of capital to improve their position relative to other agents within the field. As they engage in struggle and conflict, the configurations of power relations in fields are inscribed on individual bodies as habitus, what Bourdieu defines as transposable "mental and corporeal schemata of perception, appreciation and action" (Bourdieu and Wacquant, 1992, p.16). While habitus largely determines social practice and is moulded by fields, it is also generative and acts as a 'structuring structure' (Bourdieu, 1990) in that agents are able to transform or reinforce the structure of the field as they struggle over its rules, limits, recognised forms of capital etc.

Fields mostly tend to reproduce their structure because those in positions of power, who are able to exert control over the field, employ strategies to conserve field configurations in order to continue reaping its rewards. Those in dominated positions on the other hand, tend to engage in struggles to transform the structure of the field. Such agents draw on alternative discourses that originate outside the traditional modes of thinking of the field (Robbins, 1993) to challenge the status quo. The nature of the struggle is therefore not only for the forms of capital that are present but for the conservation or transformation of the structure of the field: 
Every field is thus the site of an ongoing clash between those who defend autonomous principles of judgment proper to that field and those who seek to introduce heteronomous standards because they need the support of external forces (Wacquant, 2008, p.269).

\section{Methodology}

This work draws on a broader study in which 21 semi-structured interviews were conducted with mainstream professors, academic development managers and foundation programme academics at two South African institutions (Kloot, 2011). Through the use of narrative analysis (Polkinghorne, 1995), the career trajectories of multiple agents were analysed to determine the structure of the field, the forms of capital that are valorised as well as the struggles and conflicting discourses that shape the field. For a number of reasons, engineering educators were interviewed for this study but the universality of the forces shaping the habitus of these academics was found to be far more significant than the characteristics of the disciplinary context of engineering. ${ }^{4}$ For this reason, these findings have relevance beyond the context of engineering and, indeed, beyond the context of the institutional boundaries of the universities chosen as case studies.

The use of narratives risks revealing respondents' identities which has certain ethical implications. To address this issue, respondents were asked to review the findings to check the factual details of the data and to confirm that they had not been misrepresented in some way. One respondent (who is not included in the 21 mentioned above) felt uncomfortable with how he was portrayed and it was agreed that his interview would not be used. However, most of the respondents were satisfied with how they were depicted and many contributed information in follow-up discussions or through email contact. Pseudonyms were used to protect the identities of the respondents.

The perspectives of two academics from a research-intensive university that we will call Emerston University, are contrasted in this article. The choice of Emerston can be considered a 'paradigmatic case' (Flyvbjerg, 2001) since, paradoxically, it is both one of the strongest research universities in South Africa and is also committed to the academic development project. This is not an unproblematic state of affairs as will be demonstrated by the contrasting 
narratives that are presented below. The entrenched positions of these agents indicate the deep-seated struggles over the structure of the field of higher education which has implications for the mode of curriculum reform proposed by the CHE.

\section{Findings and discussion}

The first academic is Prof Andrew Edmund, one of the top research professors in South African higher education and an international leader in his field. He holds a research chair, supervises large numbers of postgraduate students, has published prolifically and is well cited. These are all indicators of the large volume of intellectual capital that he possesses. As will be seen, Andrew's devotion to research, something that he describes as 'unbelievably time-consuming', shapes his practice. Consider the excerpt below in which he frankly discusses the impact this has on his approach to undergraduate teaching:

I feel the tension, I feel the demand for time. . . Now I have to make a choice: do I want to be remembered at Emerston as being this great undergraduate teacher who students all like because he's so helpful and he's always available or am I this crusty old professor who seems to brush us off the whole time. . . I'll do my best as a teacher - no, no, I'll do what's required to get most of them through but I can't get all of them through because student success rate doesn't entirely depend on my ability or inability or my time I'm spending on the students. It also depends on the time the students themselves spend on the subject. . .

It is clear that Andrew's dedication to research causes him to resist anything that may draw him away from it, including undergraduate teaching. While the potential conflict between research and teaching in higher education is not a new observation (Wong, 1995; Marsh and Hattie, 2002; Pan, Cotton and Murray, 2014), Bourdieu's framework provides a fresh perspective on this issue. Since academics have a good deal of autonomy in terms of how they structure their 'time-economy' (Bourdieu, 1988), the amount (and quality) of time they spend on activities must be understood in terms of the structure of the field and the associated system of reward. While Andrew keenly feels the 'tension', the 'demand' on his time due to activities related to undergraduate teaching, he consciously limits the time he spends on these activities and is prepared to be a 'crusty old professor' in the eyes of his undergraduates precisely because of the satisfaction and recognition that he gains from his research work. 
Whereas the autonomy of the field of higher education is aligned with research - as expressed by the maxim 'knowledge for its own sake' (Maton, 2005 ) - teaching is more closely associated with the field of secondary education and thus does not provide access to such reward. The impact on academic practice is profound. Bourdieu (1996) goes so far as to suggest that, because of the social definition of their office, university professors have "no other choice but to reject every practice that might make them seem like secondary school teachers lost in the corridors of higher education" (p.99).

It is also important to note that Andrew's disposition is coupled with a certain posture towards student autonomy, exemplified by his point that student success does not only depend on the time he spends with the students but also on the time the students themselves spend on their studies. This is in stark contrast to the habitus of academics that are employed on extended curriculum programmes. Such individuals are generally committed teachers (Niven, 2012) who dedicate time and energy to getting the very best out of their students in the hope of helping them overcome their educational disadvantage. This is certainly the case with the second academic who will be considered in this article, Mr Richard de Vos.

Richard graduated with an engineering degree from Emerston and commenced his postgraduate studies in a traditional engineering field. During his Masters he began tutoring and enjoyed it so much that he ended up running a tutoring programme for the engineering foundation programme at Emerston. After a few years he encountered problems in his Masters research but it was really his growing love for teaching, and full-time employment on the foundation programme that his Masters came to a standstill.

In the excerpt below, Richard explains the focus of the staff on the extended curriculum programme:

First and foremost, term time we teach; so everything we do in term time is about the lecture we're going to give, the workshop we are going to design around that, the contact time with the students. . .our priority is the teaching side of it for the students and that's what we have been employed to do and that's what we take very seriously. . .

Whereas Andrew was clear that he would not do his best but would 'do what is required' as a teacher, Richard is dedicated, loves his work and sees teaching as the purpose of his job; what he is 'employed to do'. 
Since undergraduate teaching in itself is neither very highly regarded nor well rewarded in the field of higher education - there is no such thing as 'teaching capital' - such a habitus is at odds with the dominant logic of the field. In the South African case, this habitus is generated and sustained by the oppositional discourse of academic development which has traditionally drawn on concerns about student equity and redress, as explained above, in order to entrench itself. Bourdieu's lens shows that this struggle for legitimation is a clash between those who defend the autonomy of the field and those who draw on alternative discourses in an effort to transform the structure of the field. The foregoing narratives give a glimpse of the deep-seated tensions that exist between research-oriented mainstream professors and foundation programme lecturers. What is at stake in this struggle are the forms of power that are valorised and the underlying structure of the field.

Given its humble origins and its history as a "highly mobile and fragmented profession" (Niven, 2012, p.139), it is not difficult to understand why academic development in South Africa has such a strong oppositional stance. Luckett, for example, notes that "due to early experiences of polarization and marginalisation, $\mathrm{AD}$ discourse tends to stereotype academics as autonomous, uncaring teachers and self-interested researchers" (2012, p.350). However, in favourable institutional contexts, academic development discourse can 'carve out' a niche within the field of higher education (Kloot, 2011) to enable the teaching-centred modes of practice described by Richard. Within such spaces, staff are insulated from the powerful effects of the field, especially the pressure to engage in research, and are able to devote themselves to the needs of their students.

Nevertheless, an unintentional consequence of defending the foundation niche from the influence of the field is that it limits the impact of academic development on its structure. Despite certain instances in which foundation work appears to have prompted change in the mainstream (Inglis, Akhurst and Barnsley, 1994; Clarence-Fincham, 2013), these changes are always localised and do not succeed in substantially transforming the structure of the field or the practice of mainstream academics. Even where progression and completion rates of students on foundation programmes is proven to be about the same as, or even better than, students from traditional entry groups (Donald and Rutherford, 1994; De Villiers and Rwigema, 1998; Garraway, 2009), the sustainability of such instances is disappointing. In fact, a recent statistically robust study shows that positive foundation programme 
completion rates are not significant when the entire qualification is considered (Smith, 2012).

This article suggests that the bridging programme model, although it has evolved in terms of its relation with the mainstream curriculum, has reached its conclusion as a foundational provision component within the flexible curriculum proposal. Moreover, a field perspective reveals this evolution in terms of a decades-long struggle over what is valorised by higher education. On the one hand is the desperate need for South Africa's universities to address the stubborn patterns of educational disadvantage that plague the sector. This paradigm values 'knowledge for the sake of others' and has driven the development of the kind of curriculum proposed recently by the $\mathrm{CHE}$ which requires the kind of teaching exemplified by Richard.

On the other hand, deeply embedded in the field of higher education itself, lies the valorisation of research which is underpinned by the maxim 'knowledge for its own sake'. This drives academics in the pursuit of intellectual capital and the kinds of approaches to teaching exemplified by Andrew. This paradigm is sustained by a global network of scholars engaged in the production of knowledge. Given the freedom that academics have in terms of how they wish to align themselves with these competing paradigms, the inevitable conclusion is that an alternative undergraduate curriculum cannot drive change - it cannot not compel mainstream academics to do anything differently.

While ' 30 years of educational development experience' can be seen as a resource to aid the success of the flexible curriculum, it is important to interrogate whether what is being proposed will be able to accomplish what 30 years of educational development has not. It is difficult to imagine that the shift from foundation programmes to foundational provision in the mode of the flexible curriculum proposal will transform the structure of the field. Indeed, this analysis suggests that entrenched modes of academic practice, in harmony with the high status of research and coupled with a particular approach to student autonomy - that the responsibility ultimately rests with the student and not with the lecturer - reinforce the operations of cultural capital to the extent that the effects of foundational provision on graduation rates are negligible. Rather than bringing about fundamental change, it appears that what will be gained on the swings of the foundation programme will be lost on the roundabout of mainstream. 


\section{Conclusion}

The sociological analysis presented above suggests that the underlying reason for the seeming lack of effectiveness of curriculum modification strategies is the power structure of higher education itself. The structure of this social space assigns a low status to undergraduate teaching and tends to resist the efforts of educational development to transform it, perpetuating modes of practice that are oriented towards the production of research outputs. While academic development in South Africa has managed to alter the structure of the field under certain circumstances, such as by carving out a foundation niche, the forms of power at work have prevented it from meaningfully transforming the structure of the field. Given the strong relationship between academic development, foundation programmes and the flexible curriculum structure proposed by the CHE, this analysis casts doubt on the likelihood of the proposed reform strategy shifting undergraduate completion rates.

Even if the recommendations in the proposal regarding staff development and capacity building (CHE, 2013) are adopted, this analysis highlights that practice is governed by what is valorised in the field and the associated systems of reward. Employing more staff or providing opportunities for upskilling in relation to curriculum design and development will do little to change the attitudes and practices of the staff already in the system. As far back as 1988, Muller drew attention to the futility of an ASP strategy that failed to pay attention to "reward and other structures that shape academic work" (1988, p.120). Given the heavy workload already on staff, it is quite possible that in many contexts the principles of the flexible curriculum will be superficially adopted and its noble intentions marginalised.

More broadly, this article highlights the danger of embracing curriculum modification as the panacea to the ills of higher education. Perhaps South Africa is unique in terms of its long history of inequitable education and the urgent requirement to adapt its higher education system to the needs to the majority population group. On the other hand, the field analysis presented here is should have relevance beyond the national particularities of South Africa. In the context of an expanding global system of higher education amid calls for widened participation and better completion rates, especially of non-traditional students, this analysis should provoke thoughtful consideration in other contexts. 


\section{References}

Amundsen, C. and Wilson, M. 2009. Academic development in higher education: a characterisation of the English-language literature. Paper presented at Society for Research into Higher Education Conference. Newport, Wales. 8-10 December.

Banks, J. and Banks, C. 1993. Multicultural education: issues and perspectives. Boston: Allyn and Bacon.

Bell, D. 1975. The coming of the post-industrial society. New York: Basic Books.

Blackmore, P. and Kandiko, C. 2012. Strategic curriculum change in universities: global trends. Oxon: Routledge.

Boughey, C. 2007. Analysis of extended curriculum programme submissions. Unpublished seminar paper. Cape Peninsula University of Technology (Bellville).

Boughey, C. 2012. The significance of structure, culture and agency in supporting and developing student learning at South African universities. In Dhunpath, R. and Vithal, R. (Eds). Alternative access to higher education: underprepared students or underprepared institutions? Cape Town: Pearson.

Boughey, C. 2013. Real barrier is academic inertia. Getting Ahead Supplement, Mail and Guardian, 4 October.

Bourdieu, P. 1988. Homo academicus. Cambridge: Polity Press.

Bourdieu, P. 1990. The logic of practice. Cambridge: Polity Press.

Bourdieu, P. 1996. The state nobility: elite schools in the field of power. Cambridge: Polity Press.

Bourdieu, P. and Passeron, J-C. 1977. Reproduction in education, society and culture. London: Sage. 
Bourdieu, P. and Wacquant, L. 1992. An invitation to reflexive sociology. Chicago: University of Chicago Press.

Brew, A. 2002. The changing face of academic development. The International Journal for Academic Development 7(1): pp.5-6.

CHE, 2004. South African higher education in the first decade of democracy. Pretoria: Council on Higher Education.

CHE, 2013. A proposal for undergraduate curriculum reform in South Africa: the case for a flexible curriculum structure. Report of the Task Team on Undergraduate Curriculum Structure. Pretoria: Council of Higher Education.

Clarence-Fincham, J. 2013. Developing an extended curriculum for humanities at the University of KwaZulu-Natal: conceptual shifts, challenges and constraints. Journal for the New Generation Sciences, 7(3): pp.70-83.

Clegg, S. 2009. Histories and institutional change: understanding academic development practices in the global 'north' and 'south'. International Studies in Sociology of Education, 19(1): pp.53-65.

Clewell, B. and Ficklan, M. 1986. Improving minority retention in higher education. Report for Educational Testing Service. Princeton: New Jersey.

Davies, J. 1996. The state and the South African university system under apartheid. Comparative Education, 32(3): pp.319-332.

Department of Education (DoE), 1997. A programme for the transformation of higher education (Education Draft White Paper 3). Pretoria: Department of Education.

Department of Education (DoE), 2006. Funding for foundational provision in formally approved programmes: 2007/8 to 2009/10. Pretoria: Department of Education.

De Villiers, J. and Rwigema, H. 1998. The effect of a bridging year on the graduation success of educationally disadvantaged commerce students. South African Journal of Higher Education, 12(1): pp.103-108. 
Donald, C. and Rutherford, M. 1994. Evaluation of the first year of a college of science. South African Journal of Higher Education, 8(2): pp.45-53.

Finegold, D. and Soskice, D. 1988. The failure of training in Britain: analysis and prescription. Oxford Review of Economic Policy, 4(3): pp.21-53.

Flyvbjerg, B. 2001. Making social science matter: why social inquiry fails and how it can succeed again. Cambridge: Cambridge University Press.

Garraway, J. 2009. Success stories in foundation/extended programmes. Cape Town: Higher Education Learning and Teaching Association of Southern Africa.

Grayson, D. 1996. A holistic approach to preparing disadvantaged students to succeed in tertiary science studies. Part I. Design of the Science Foundation Programme. International Journal of Science Education, 18(8): pp.993-1013.

Harvey, L. 2009. Review of research literature focussed on Foundation degrees. Review done on behalf of Foundation Degrees Forward.

HEFCE, 2013. International research on the effectiveness of widening participation. Report to Higher Education Funding Council of England and Office for Fair Access by CFE (Research and Consulting) and Edge Hill University.

Inglis, M., Akhurst, J. and Barnsley, S. 1994. Mainstreaming foundational courses in the Faculty of Science. Paper presented at the 9th Annual South African Association for Academic Development Conference, 31 August1 September.

Kotecha, P., Allie, S. and Volmink, J. 1997. Narset Report: Issues relating to access and retention in science, engineering and technology in higher education. Pretoria: Department of Arts, Culture, Science and Technology.

Kloot, B. 2011. A Bourdieuian analysis of foundation programmes in the field of engineering education: two South African case studies. Unpublished PhD thesis: University of Cape Town. 
Luckett, K. 2012. Working with 'necessary contradictions': a social realist meta-analysis of an academic development programme review. Higher Education Research and Development, 31(3): pp.339-352.

Marsh, H. and Hattie, J. 2002. The relation between research productivity and teaching effectiveness: complementary, antagonistic, or independent constructs? The Journal of Higher Education, 73(5): pp.603-641.

Maton, K. 2005. A question of autonomy: Bourdieu's field approach and higher education policy. Journal of Education Policy, 20(6): pp.687-704.

Morey, A. 2000. Changing higher education curricula for a global and multicultural world. Higher Education in Europe, 25(1): pp.25-39.

Morey, M. and Kitano, M. 1997. Multicultural course transformation in higher education: a broader truth. Boston: Allyn and Bacon.

Muller, J. 1988. Coming in from the margins: options for ASP in a pluralist university. Paper presented at the ASPects 9 Conference. Cape Town: University of Cape Town.

Niven, P. 2012. Narrating emergence in the curious terrain of academic development research: a realist perspective. Unpublished $\mathrm{PhD}$ thesis. Grahamstown: Rhodes University.

Ognibene, E. 1989. Integrating the curriculum: from impossible to possible. College Teaching, 37(3): pp.105-110.

Pan, W., Cotton, D. and Murray, P. 2014. Linking research and teaching: context, conflict and complementarity. Innovations in Education and Teaching International, 51(1): pp.3-14.

Pegg, A. 2013. "We think that's the future": curriculum reform initiatives in higher education. Centre for Inclusion and Collaborative Partnerships, The Open University. York: Higher Education Academy.

Phillips, H. 2003. A Caledonian college in Cape Town and beyond: an investigation into the foundation(s) of the South African university system. South African Journal of Higher Education, 17(2): pp.122-128. 
Polkinghorne, D. 1995. Narrative configuration in qualitative analysis. International Journal of Qualitative Studies in Education, 8(1): pp.5-23.

Robbins, D. 1993. The practical importance of Bourdieu's analyses of higher education. Studies in Higher Education, 18(2): pp.151-163.

Rollnick, M. 2010. Identifying potential for equitable access to tertiary level science: digging for gold. Dordrecht: Springer.

Saunders, S. 2011. The closed doors of academe. Mail and Guardian, July $15-21$.

Schofer, E. and Meyer, J. 2005. The worldwide expansion of higher education in the twentieth century. American Sociological Review, 70(6): pp.898-920.

Scott, I. 1986. Tinkering or transforming? The contribution of academic support programmes to 'opening the doors of learning and culture'. Paper presented at ASPects 7 Conference. Pietermaritzburg: University of Natal.

Scott, I. 2001. Public funding for academic development: analysis and proposals, individual submission to the Ministry of Education in response to the 2001 discussion document 'Funding of Public Higher Education: A New Framework'. Cape Town: University of Cape Town.

Scott, I., Yeld, N. and Hendry, J. 2007. A case for improving teaching and learning in South African higher education. Higher Education Monitor No. 6, Pretoria: Council on Higher Education.

Shay, S. 2014. Time for matriculants to handle next chapter in their education. Sunday Debate Supplement, Sunday Independent, 12 January.

Smith, L. 2012. The effect of selected academic development programmes on the academic performance of academic development students at a South African university: an empirical analysis. Unpublished $\mathrm{PhD}$ thesis: University of Cape Town.

Stanton, M. 1987. An evaluation of a first-year half-course in physics for bridging students at the University of the Witwatersrand. South African Journal of Higher Education, 1(1): pp.105-111. 
Tinto, V. 1975. Dropout from higher education: a theoretical synthesis of recent research. Review of Educational Research, 45: pp.89-125.

Unterhalter, E. and Carpentier, V. 2010. Global inequalities and higher education: whose interests are we serving? London: Palgrave MacMillan.

Volbrecht, T. and Boughey, C. 2004. Curriculum responsiveness from the margins? A reappraisal of academic development in South Africa. In Griesel, H. (Ed.). Curriculum responsiveness: case studies in higher education. Pretoria: South African Universities Vice-Chancellors Association.

Wacquant, L. 2008. Pierre Bourdieu. In Stones, R. (Ed.). Key sociological thinkers. London: Palgrave MacMillan.

Wangenge-Ouma, G. 2013. Widening participation in South Africa. International Research on the Effectiveness of Widening Participation. Bristol: HEFCE.

Warren, D. 2002. Curriculum design in a context of widening participation in higher education. Arts and Humanities in Higher Education, 1(1): pp.85-99.

Wong, E. 1995. Challenges confronting the researcher/teacher: conflict of purpose and conduct. Educational Researcher, 24(3): pp.22-28.

Bruce Kloot

Centre for Research in Engineering Education

Faculty of Engineering and the Built Environment

University of Cape Town

bruce.kloot@uct.ac.za 